\title{
INVESTIGAÇÃO DE FOCO, UMA DAS ATIVIDADES DAS CAMPANHAS DE CONTROLE DOS TRANSMISSORES DA TRIPANOSSOMIASE AMERICANA
}

Eduardo Olavo da Rocha e Silva * José Carlos Rehder de Andrade* Vera Lúcia C. C. Rodrigues*

Rocha E Silva, E. O. da et al. Investigação de foco, uma das atividades das campanhas de controle dos transmissores da tripanossomiase americana. Rev. Saúde públ., S. Paulo, 12:425-31, 1978.

Resumo: A entrega à Superintendência de Controle de Endemias por um morador do Municipio do Espirito Santo do Pinhal, Estado de São Paulo (Brasil), de um inseto suspeito de "barbeiro", encontrado na casa (quarto), sua correta identificação e exame, P. megistus infectado por Trypanosoma tipo cruzi, desencadeou uma operação de "investigação de foco", realizada através de operaçóes de campo e laboratório. Esses trabalhos evidenciaram a presença da enzootia chagásica naquela localidade, bem como, a possibilidade do $\mathrm{T}$. cruzi chegar aos sells moradores. Tal não ocorrendo, entre outros fatores, em decorrência das atividades de controle em andamento. Foi destacado o valor da "denúncia" (notificaçáo) feita pelo morador $e$ relatadas atividades ligadas à investigação de foco.

Unitermos: Tripanossomiase americana. Panstrongylus megistus. Triatomineos, controle.

I N T RODU Ç Ã O

Em publicação recente, Forattini et al. ${ }^{2}$ (1977) mostraram a capacidade apresentada por algumas populações do Panstrongylus megistus Burmeister, 1835, de formar colônias em ecótopos artificiais a partir de focos extradomiciliares. É também sobejamente conhecido o fato dos marsupiais, na natureza, funcionarem como reservatórios importantes do Trypanosoma cruzi (Barretto ${ }^{1}$, 1976). Por outro lado, achados freqüentes de gambás do gênero Didelphis, ao lado de exemplares do $P$. megistus, inclusive encontrados junto ao homem, permitiram a Rocha e Silva e col.8 (1975) e Forattini e col.4 (1977) chamarem atenção para a possibilidade da reintrodução do ciclo domiciliado do parasito, em áreas atualmente limpas da endemia.

Concluída com auxílio do inseticida, a operação dirigida a eliminar o vetor domiciliado ( $T$. infestans), e considerada irrelevante na área a presença nas moradias $e$ anexos dos exemplares das espécies ditas semidomiciliadas ( $T$. sordida e $P$. megistus), passa a não ter mais sentido a manutenção dos expurgos periódicos, de todas as casas,

* Da Diretoria de Combate a Vetores, da Superintendência de Controle de Endemias (SUCEN) do Estado de São Paulo - Rua Tamandaré, 649 - 01525 - São Paulo, SP - Brasil. 
ROCHA E SILVA, E. O. da et al. Investigação de foco, uma das atividades das campanhas de controle dos transmissores da tripanossomíase americana. Rev. Saúde públ., $\mathrm{S}$. Paulo, 12 : 425-31, 1978

a título de controle da endemia. A medida que se impõe a partir desse momento, é a procura de casa em casa (inclusive anexos) dos novos ou eventuais focos residuais, seguida no caso positivo do expurgo seletivo. No entretanto, essa tática de combate aos transmissores vai no tempo se tornando rotineira e onerosa, particularmente se tomada no sentido estritamente econômico, tão em moda em nossos dias, a ponto do exito ser avaliado pela simples relação: custo global/focos encontrados. Restando pois à vigilância, como armas básicas, a utilização das "buscas por amostragem" e a "notificação de foco" (denúncia). Esta última, fruto da participação ativa e deliberada da população, deverá desencadear quando deflagrada, rápida ação resposta da autoridade sanitária.

Neste trabalho não está sendo apresentado o processo de instalaçāo e funcionamento do sistema de denúncia de focos, já descrito por Rocha e Silva e col. ? (1971), mas sim, certas atividades que o atendimento de uma denúncia permitem realizar, trazendo satisfação aos moradores e subsídios de natureza epidemiológica aos técnicos, através da investigação do foco. São pois apresentadas aqui, algumas das tarefas de campo e laboratório que o serviço de controle dos transmissores da tripanossomíase americana deve realizar nas áreas limpas do vetor domiciliado, quando do encontro de outra espécie de triatomíneo, infectada, nas casas habitadas.

\section{MATERIAL E METODOS}

A denúncia no caso presente se concretizou, pela entrega ao laboratório da Superintendência de Controle de Endemias (SUCEN), localizado em Moji Guaçu, de inseto suspeito de ser "barbeiro". Efetuada a identificação, comprovou-se tratar efetivamente de um triatomíneo, exemplar alado, fêmea, do $P$. megistus, capturado vivo em $11 / 11 / 76$, pelo próprio morador, no quarto (cama), casa 29 da Fazenda Santa Tereza,
Município de Espírito Santo do Pinhal, Estado de São Paulo (Figura 1). Examinado seu conteúdo intestinal, observou-se a presença de formas flageladas livres. Reexaminado, após fixação pelo soro humano inativado e coloração pelo May-Grünwald-Giemsa, tais formações apresentaram caracteristicas morfológicas de Trypanosoma tipo cruzi. A reação de precipitina (tubos capilares), para identificação do tipo de sangue ingerido, realizada diante de uma bateria de seis diferentes anti-soros, apresentou positividade apenas frente ao sangue humano.

Esses achados desencadearam uma operação típica de "investigação de foco", processando-se a mesma através da realização de tarefas desenvolvidas, concomitantemente, em duas frentes distintas, a saber:

\section{a) no campo (Fazenda Santa Tereza)}

- pesquisa de triatomíneos nos ecótopos artificiais;

- pesquisa análoga, em relação a alguns ecótopos naturais;

- exame de animais domésticos, através da realização de xenodiagnóstico;

- captura e exame de mamíferos sinantrópicos e silvestres;

- coleta de sangue de moradores, para reação sorológica;

b) no laboratório (Moji Guaçu)

- identificação de triatomíneos;

- pesquisa da infecção natural nos triatomíneos, recebidos e coletados;

- reações de precipitina para identificação do tipo de sangue ingerido pelos triatomineos;

- exame dos xenodiagnósticos realizados;

- inoculação de cepas em pequenos animais de laboratório; 
ROCHA E SILVA, E. O. da et al. Investigação de foco, uma das atividades das campanhas de controle dos transmissores da tripanossomiase americana. Rev. Saúde públ., $\mathrm{S}$. Paulo, 12: 425-31, 1978.

- estudo biomorfológico de uma das cepas;

- cultivo dessa mesma cepa, em meio de Warren;
- preparação de lâminas e leituras de cortes histológicos;

- diagnóstico da infecção chagásica, pela técnica de imunofluorescência indireta (SUCEN, S. Paulo).

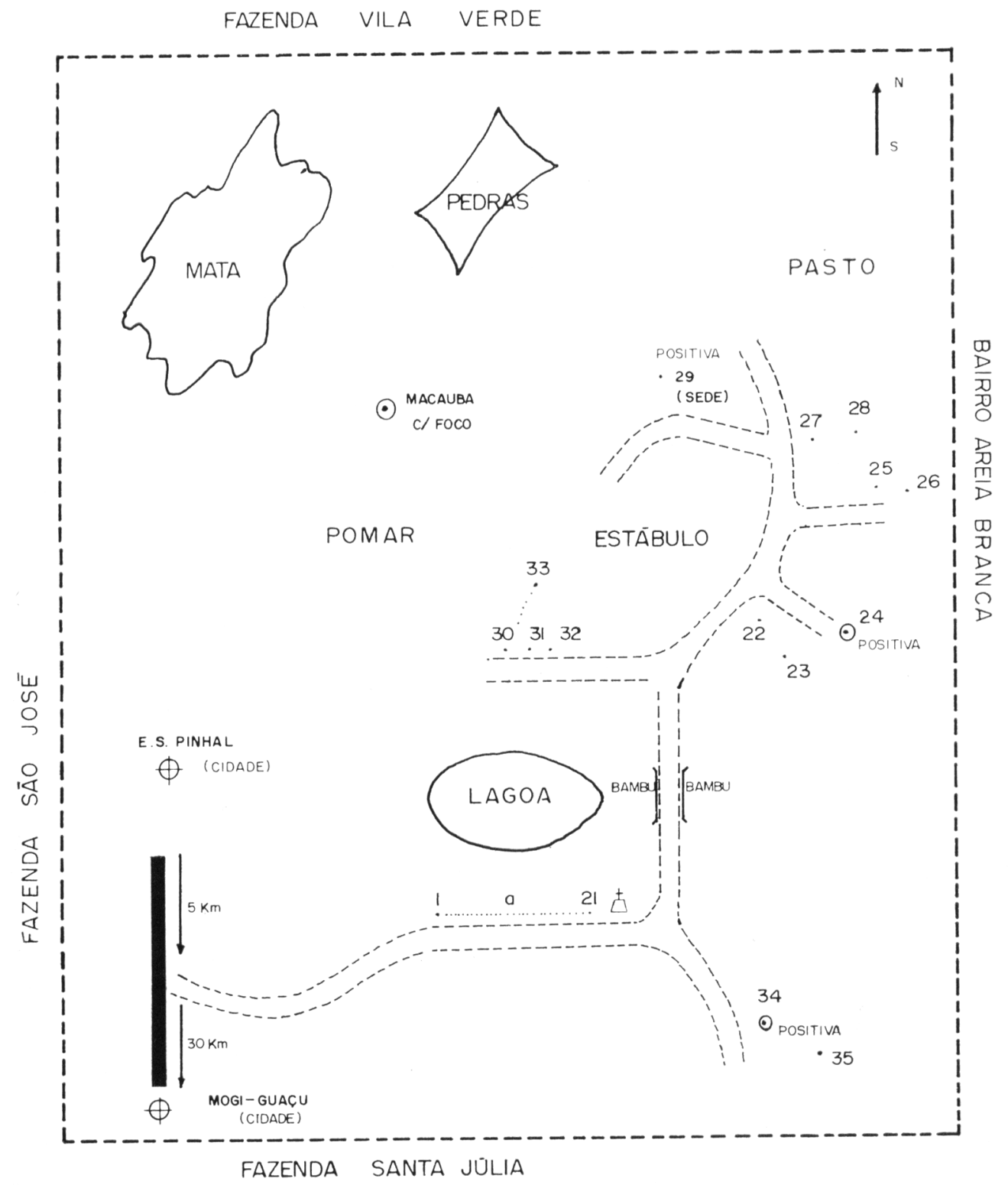

Croquis da Fazenda Santa Tereza, Municipio de Espirito Santo do Pinhal, SP, Brasil. 
ROCHA E SILVA, E. O. da et al. Investigação de foco, uma das atividades das campanhas de controle dos transmissores da tripanossomíase americana. Rev. Saúde públ., S. Paulo, 12: 425-31, 1978.

\section{RESULTADOS}

Como medida imediata e rotineira de atendimento à denúncia, foi efetuada pelo pessoal de campo da SUCEN (Serviço Regional 5) a procura de outros exemplares, não apenas na casa que desencadeou o processo, como também em outras existentes na localidade. O resultado dessa busca mostrou-se, naquele momento, negativa. Vale salientar que, em ano anterior, havia sido descoberto na localidade um grande foco, em um anexo à sede da Fazenda, situado próximo ao pomar.

Após os primeiros resultados negativos, pesquisa levada a efeito entre alguns possiveis habitáculos naturais da espécie, na área, levou ao encontro de um foco de triatomineos no topo de uma palmeira "macauba" (Acrocomia), localizada no pomar da Fazenda, não muito distante da habitação positiva. Ressalte-se que este foco se situava próximo de uma "mancha" de mata, sendo ali encontrados $6 P$. megistus, 4 alados (2 하 o e 2 우 우) e 2 ninfas (5\% estádio), todos observados infectados por $T$. tipo cruzi. Os testes de precipitina, realizados no sentido de revelar o tipo de sangue no conteúdo intestinal, contra soros anti-sangue humano, cão, gato, galinha, rato e gambá, mostraram nos seis exemplares positividade apenas para sangue de marsupial.

Enı unı dos extremos da propriedade, em local distante da área onde estão situadas as 35 casas, construídas com tijolos, foram capturados entre pedras, 22 exemplares do $T$. arthurneivai que se mostraram ao exame, negativos para tripanosomatideos. No mesmo lugar, foi capturado também um lagarto (Tropidurus torquatus) que apresentava hemácias parasitadas por Plasmodium, provavelmente o $P$. (S) tropi$d u r i$, anteriormente encontrado no município por Rocha e Silva e Rodrigues ${ }^{6}$ (1974).

No decorrer dos trabalhos, outro residente na propriedade, encontrou em sua casa (casa 34), um $P$. megistus alado, fêmea, no chão do dormitório. Ao exame, mostrou-se como os anteriores, positivo para T. tipo cruzi. Porém, o material presente no tubo digestivo foi insuficiente para os testes de precipitina, possivelmente, por se tratar de adulto jovem, não alimentado.

Tendo em vista os resultados alcançados pelos exames de precipitina e conhecimentos disponiveis sobre os hábitos da espécie em pauta, partiu-se para a captura e exame (gotas de sangue e xenodiagnóstico) de animais silvestres. Através da instalação de armadilhas em locais adequados, foram capturados 10 exemplares de gambás, do gênero Didelphis. Três deles, identificados como D. marsupialis e os sete restantes como D. azarae. Dos últimos, quatro $(57,14 \%)$ mostraram-se, através dos xenodiagnósticos, positivos para $T$. tipo cruzi.

$\mathrm{Na}$ ocasião, apenas um roedor (Rattus rattus) foi capturado, observado parasitado pelo $T$. lewisi, comprovado em laboratório pela fácil infecção, por via intraperitonial, de ratos brancos e não infecção de camundongos. Simultaneamente com a realização das capturas, efetuaram-se também xenodiagnósticos nos 8 cães e 2 gatos encontrados nas residências, resultando todos negativos. Nos xenos, foram utilizadas ninfas de 40 e $5^{\circ}$ estádio do $T$. megistus e $T$. infestans, colocados 10 exemplares, por espécie, em cada caixa e usadas duas por animal examinado.

As cepas outidas dos $P$. megistus e de 2 dos marsupiais encontrados infectados, permitiram a realização, em laboratório, das seguintes observações:

a) do exemplar responsável pela denúncia, obteve-se em ratos brancos jovens, após dez dias da inoculação, parasitemias detectáveis no sangue periférico. Nos esfregaços de sangue, corados, preparados com esse material, observou-se a presença de tripanossomos com morfologia semelhante ao $T$. cruzi;

b) através de inoculações sucessivas em ratos e acompanhamento da curva parasitêmica, inclusive comparada com ca- 
ROCHA E SILVA, E. O. da et al. Investigação de foco, uma das atividades das campanhas de controle dos transmissores da tripanossomíase americana. Rev. Saúde públ., S. Paulo, 12: $425-31,1978$.

mundongos jovens, foi notada intensidade maior da infecção nos ratos. A mortalidade, no entretanto, atingiu $40 \%$ dos ratos até o trigésimo dia após a inoculação e mais de $80 \%$ dos camundongos. Na fase aguda, o pique parasitêmico ocorreu nos ratos entre $012^{\circ}$ e $20^{\circ}$ dia após a inoculação e nos camundongos, entre o $15^{\circ}$ e $22^{\circ}$ dia;

c) com esta mesma cepa, foram realizadas diversas semeaduras em meio de Warren, obtendo-se culturas ricas em parasitos;

d) "pool" do material intestinal, dos seis exemplares capturados na "macauba", foi inoculado em ratos brancos. Posteriormente, foram realizados cortes histológicos, mostrando a presença de formas amastigotas no coração;

e) o material intestinal retirado do outro exemplar, capturado no interior de uma casa, também positivou os ratos inoculados com formas sanguícolas e teciduais;

f) as formas flageladas, presentes nos triatomíneos utilizados nos xenodiagnósticos de 2 dos gambás positivos, determinaram o aparecimento de tripanossomos circulantes (sangue) nos ratos inoculados.

Finalmente, foram colhidas gotas de sangue em papel de filtro, de 4 moradores das casas invadidas pelos $P$. megistus. Através dos exames de imunofluorescência indireta, realizados em laboratório especializado, constatou-se a negatividade dos mesmos.

\section{COMENTÁRIOS}

O encontro pelo morador, de exemplar de triatomíneo no intradomicilio, em área limpa do $T$. infestans e a conseqüente denúncia ao serviço competente, no caso a SUCEN, determinou rotineira ação local de pesquisa e combate ao foco. Isto satisfez a comunidade atingida, como em parte também aos responsáveis pelo controle dos transmissores da endemia chagásica. No caso presente, as medidas de rotina foram acompanhadas, em caráter experimental, de outras, objetivando alargar conhecimentos sobre o foco.

O município de Espírito Santo do Pinhal, como outros localizados na região nordeste do Estado, limitrofe com Minas Gerais, em anos anteriores foi alvo de periódica campanha antitriatomínica realizada com a aplicação de inseticida $(\mathrm{HCH} 30 \%)$, resultando na eliminação do $T$. infestans. No entretanto, o mesmo não ocorreu em relação ao $P$. megistus, constituindo-se as manchas de matas residuais, ali presentes, em seus refúgios, de onde a espécie se dispersa graças à mobilidade ativa, apreciável valência ecológica, ecletismo alimentar, condiçōes climáticas $e$ as alterações ambientais (Forattini e col.5 1978). Reporte-se que o município em questão se localiza na zona de clima tropical, apresentando verão úmido e inverno seco, situando-se na faixa de transição climática centro-sul do pais. $\mathrm{Da}$ primitiva cobertura vegetal, formada por amplas florestas latifoliadas, restam apenas manchas residuais que não cobrem mais de $10 \%$ do território (Secretaria da Economia e Planejamento 9,1972 ).

No caso particular da Fazenda Santa Tereza, constatou-se a existência de uma mancha de mata residual, reservatórios silvestres (gambás) e $P$. megistus infectados, encontrados inclusive, em terreno modificado. Em decorrência, nos meses propícios à dispersão do triatomíneo (Forattini, e col. ${ }^{3}$ 1977), os alados partem em busca de novos habitáculos, podendo invadir, como ficou constatado, ecótopos artificiais próximos (casas habitadas, chegando até ao repasto humano).

As medidas de controle, a presença de moradores conhecedores do vetor e fatores outros, como: tipo de habitação, higiene, etc., vêm impedindo que a invasão se faça acompanhar da formação de colônias, nas casas, reduzindo-se assim a possibilidade de infecção dos animais domésticos e do homem, na área. Essas medidas, ao que 
ROCHA E SILVA, E. O. da et al. Investigação de foco, uma das atividades das campanhas de controle dos transmissores da tripanossomíase americana, Rev. Saúde públ., S. Paulo, 12: 425-31, 1978.

tudo indica, terão seguimento até que as alteraçōes ambientais atuem, acentuadamente, sobre a sobrevida do transmissor e/olt dos reservatórios silvestres.

\section{CONCLUSOES}

1. A localidade está situada em área onde se faz presente a tripanossomíase americana, constatada na sua forma enzoótica.

2. A "denúncia" (notificação) pelos moradores e conseqüente "investigação de foco", representam medidas de interesse para as campanhas de controle dos transmissores.

3. A "investigação do foco" exige a presença de laboratório apropriado e pessoal habilitado.

\section{AGRADECIMENTOS}

Ao Sr. Clóvis Joly de Lima, proprietário da Fazenda Santa Tereza, em Espírito Santo do Pinhal, bem como ao técnico da SUCEN, Sr. José de Campos Camargo, pela colaboração.

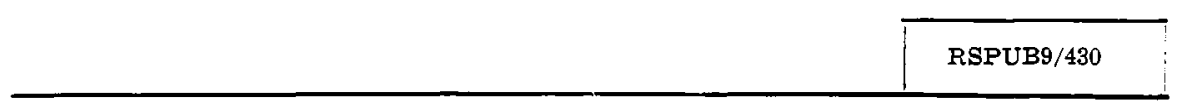

Rocha E Silva, E. O. da et al. IFocal point investigation one of the activities of the campaigns for control over the transmitters of American Trypanosomiasis] Rev. Saúde públ., S. Paulo, 12:425-31, 1978.

ABSTRACT: The delivery to the Superintendencia de Controle de Endemias (SUCEN) of an insect suspected of being the "barbeiro", the transmitter of the Chagas' disease, unleashed a focal point investigation with laboratory and field operations. The insect had been found in the house of the person who had brought it in; examination showed it to be the "barbeiro", that is, P. megistus, infected with Trypanosoma cruzi. Investigation proved the enzootic presence of South American Trypanosomiasis in the area and the possibility of houses being invaded by the T. cruzi. This was avoided through controls put into effect immediately, showing the importance of promptly informing the health agency responsible and thorough follow-up by health authorities.

UNITERMS: Trypanosomiasis, South American. Panstrongylus megistus. Triatominae control.

\section{REFERENCIAS BIBLIOGRAFICAS}

1. BARRETTO, M. P. Possible role of wild mammals and triatomines in the transmission of Trypanosoma eruzi to man. In: International Symposium on New Approaches in American Trypanosomiasis Research. Belo Horizonte, 1975. Proceedings. Washington, D. C., Pan American Health Organization, 1976. p. 306-16. (PAHO - Scient. publ., 318).

2. FORATtiNI, O. P. et al. Aspectos ecologicos da Tripanossomiase americana.
VIII - Domiciliação de Panstrongylus megistus e sua presença extra-domiciliar. Rev. Saúde públ., S. Paulo, 11: $73-86,1977$.

3. FORATTINI, O. P. et al. Aspectos ecolbgicos da Tripanossomiase americana. $\mathrm{X}$ - Dados populacionais das colonias de Panstrongylus megistus e de Triatoma sordida espontaneamente desenvolvidas em ecótopos artificiais. Rev. Saúde públ., S. Paulo, 11:362-74, 1977. 
ROCHA E SILVA, E. O. da et al. Investigação de foco, uma das atividades das campanhas de controle dos transmissores da tripanossomiase americana. Rev. Saúde publ., $\mathrm{S}$. Paulo, 12 : 425-31. 1978 .

4. Forattini, O. P. et al, Aspectos ecológicos da Tripanossomíase americana. $\mathrm{XI}$ - Domiciliação de Panstrongylus megistus e potencial enzoótico. Rer. saude puibl., S. Paulo, 11:527-50, 1977.

5. FORAtTiNi, $O, P$. et al. Aspectos ecológicos da Tripanossomíase americana. XII - Variação regional da tendência do Panstrongylus megistus à domiciliaçāo. Rer. Saúde públ., S. Paulo. $12: 209-33,1978$.

6. ROCHA E SILVA, E. O, da \& RODRIGUES, D. de C. Encontro do Plasmodium (S) tropiduri no Estado de São Paulo. Brasil. Rer. Saúde públ., S. Paulo, 8 163-70, 1974 .
7. ROCHA E SILVA, E. O. da et al. La enfermedad de Chagas. Vigilância entomológica en el Estado de São Paulo, Brasil. Bol. Ofic. sanit, panamer., $71: 387-401,1971$

8. ROCHA E SILVA, E. O. da et al. Importância dos animais sinantrópicos no controle da endemia chagásica. Rex. Saúde públ., S. Paulo, 9:371-81. 1975.

9. SECRETARIA DE ECONOMIA E PLANEJAMENTO. Diagnóstica. $V$ Regiāo Administratı́a. São Paulo. 1972.

Recebido para publicação em 21/06/1978 A provado para publicação em $09 / 08 / 1978$ 